\title{
〈研究ノート〉
}

\section{Differences in Response to Productivity Shock Depending on Economic Development Stages}

Inyong Shin*

\begin{abstract}
In many previous studies of real business cycle, economy has been analyzed only near steady state. This research adds an analysis on transitional path to the analysis near steady state. This research analyzes the size of responses of economic variables to productivity shocks depending on development stages. Economic scale is different depending on the development stages, therefore, the size of the volatility of economic variables is also quite different even though the same shock occurs. The volatility of consumption and capital stock at the early development stage can be overestimated comparing to the volatility near steady state. On the other hand, the volatility of labor and investment at the early development stage can be underestimated comparing to the volatility near steady state.
\end{abstract}

JEL Classification: E32, E27, C63

Keywords: real business cycle; steady state; transitional path; productivity shock; half of steady state level of capital stock; state-dependent

\section{Introduction}

Are the effects of external productivity shock on economic variables the same or not when the same shock occurs in countries which are at different development stages? This research will offer answers to the question. The sizes of responses of economic variables to the common shock are quite different depending on the development stages. This research investigates the differences of the responses of the economic variables against the same external shock when it occurs in developed countries and developing countries.

Most real business cycle (RBC) studies, starting with Kydland and Prescott (1982) and King, Plosser and Rebelo (1988), etc., focus on analysis near steady state. They take approximation methods near steady state and analyze how much economic variables deviate

* Department of Economics, Asia University, 5-24-10 Sakai Musashino Tokyo 180-8629 Japan, email: shin@asia-u.ac.jp, URL: http://www2.asia-u.ac.jp/ shin 
from the steady state against external shocks. In addition to the analysis near steady state, we assume an economy on a transitional path which is far from steady state and calculate how much economic variables deviate from the transitional path when external productivity shocks occur. This research compares the size of the volatility of economic variables when the external shocks occur not only near steady state but also on transitional path. This point is new and different from previous research.

Except for few developed countries, most countries do not reach their steady state. If many countries are still on their transitional path, it would be more appropriate for those countries to analyze the movement of economic variables on their transitional path than to analyze the movement near their steady state which is still ahead.

In this research, we analyze the difference between the fluctuation near the steady state and the fluctuation on transitional path using the basic RBC model. We found that the degree of responses of economic variables to the same external productivity shock, which affects the same percent of output, varied considerably depending on the development stages. The results obtained in this research are summarized as follows; 1) The volatility of consumption and capital stock on transitional path is overestimated comparing to the volatility near steady state. 2) On the other hand, the volatility of labor and investment on transitional path is underestimated comparing to the volatility near steady state. The results imply that there are differences in volatility of the economies depending on whether they analyze it at the steady state or while being on a transitional path. As these differences exist it is recommended that the countries take it into consideration for making decisions regarding the economic policies.

This research contributes to report that in the basic RBC model, the response of economic variables to an exogenous TFP shocks is state-dependent. This restult has great implications for developing countries. It is important to highlight that in this research, we will not address the possible mechanisms behind the obtained results theoretically. This research is about making a note on the results and the possible mechanisms will be studied in the future research papers.

This note is organized as follows: Section 2 introduces the basic RBC model. Section 3 compares the volatility obtained near steady state with the volatility obtained at early stage of development. And, Section 4 offers conclusions on this research. 


\section{Basic RBC model}

In this research, we deal with the basic RBC model. The RBC model is an endogenous model that introduces the labor supply into Ramsey-Cass-Koopmans model, which is the simplest dynamic model with labor supply and capital accumulation including micro-foundation.

Section 2 describes the basic RBC model briefly. There is no author's originality in Section 2. Symbols of economic variables and parameters used in this research follow the symbol notations commonly used in economics. $t, C, L, K, Y, r, w, A, \alpha, \beta, \delta, \rho, \epsilon$ and $\gamma$ mean time, consumption, labor, capital stock, output, interest rate, wage rate, productivity, capital share, discount factor, depreciation rate, persistence of technology shock, technology shock and a parameter that measures the relative weight of leisure in the utility function, respectively.

In this research, in order to avoid using the approximation methods near steady state (Blanchard and Kahn (1980), Kydland and Prescott (1982), Uhlig (1999), Klein (2000), Sims (2002), etc.), we use the grid search method covering wide ranges ${ }^{1)}$. For the details about the grid search to solve the model, please refer to Judd (1998), McCandless (2008), Heer and Maussner (2009) etc.

The model is as follows.

- Household

$$
\begin{aligned}
& \max _{C_{t}, L_{t}} E_{0}\left[\sum_{t=0}^{\infty} \beta^{t}\left(\ln C_{t}+\gamma \ln \left(1-L_{t}\right)\right)\right] \\
& C_{t}+K_{t+1}=r_{t} K_{t}+w_{t} L_{t}+(1-\delta) K_{t}
\end{aligned}
$$

- Firm

$$
Y_{t}=B A_{t} K_{t}^{\alpha} L_{t}^{1-\alpha}
$$

- market equilibrium

$$
\begin{aligned}
& r_{t}=\alpha B A_{t} K_{t}^{\alpha-1} L_{t}^{1-\alpha}=\alpha \frac{Y_{t}}{K_{t}} \\
& w_{t}=(1-\alpha) B A_{t} K_{t}^{\alpha} L_{t}^{\alpha}=(1-\alpha) \frac{Y_{t}}{L_{t}}
\end{aligned}
$$

- productivity shock

1) Quadratic approximation of the utility function (Kydland and Prescott (1982)), Eigenvalue Decomposition (Blanchard and Kahn (1980)), Generalized Schur (or QZ) Decomposition (Klein (2000), Sims (2002)), etc. 


$$
\ln A_{t+1}=\rho \ln A_{t}+\epsilon_{t+1}
$$

Eq. (1) is a utility function, Eq. (2) is a budget constraint equation, Eq. (3) is a production function, Eq. (4) and Eq. (5) are profit maximization conditions, Eq. (6) is a technology process which evolves as a first order autoregressive stochastic process. $\epsilon$ is an i.i.d. standard normal process. And, $B$ is a constant, $B=\frac{1}{(1-\alpha)^{1-\alpha} \alpha \beta}(1-$ $\beta+\beta \delta)^{\alpha}((1-\alpha+\gamma)(1-\beta+\beta \delta)-\alpha \beta \gamma \delta)^{1-\alpha}$. At the steady state, $A_{t}=A_{t+1}=A^{s s}$, $\epsilon_{t}=\epsilon_{t+1}=0$, then, because $\ln A^{s s}=\rho \ln A^{s s}, A^{s s}=1$. The $s s$ in superscript means steady state. The labor at the steady state $L^{s s}$ and the capital stock at steady state $K^{s s}$ are $L^{s s}=\frac{(1-\alpha)(1-\beta+\beta \delta)}{(1-\alpha+\gamma)(1-\beta+\beta \delta)-\alpha \beta \gamma \delta}$ and $K^{s s}=\frac{(1-\alpha)(1-\beta+\beta \delta)^{\frac{\alpha}{\alpha-1}}(\alpha B \beta)^{\frac{1}{1-\alpha}}}{(1-\alpha+\gamma)(1-\beta+\beta \delta)-\alpha \beta \gamma \delta}=1$, respectively.

\section{Results}

We analyze the results numerically. The parameter values for numerical calculation are set as follows; $\beta=0.99, \delta=0.025, \alpha=\frac{1}{3}, \rho=0.9, \gamma=2$ and $\epsilon \sim N(0,0.05)$. These values are well known as the parameter values for numerical calculation. The initial value of the transitional path was set to the half of steady state level of capital stock. Since the value of the capital stock at the steady state is 1.0 , the initial value of the capital stock $\left(K_{0}\right)$ was set to 0.5 . We summarize the values in Table 1 .

Table 1 the values of economic variables at steady state, the initial value of capital stock and $B$

\begin{tabular}{c|c|c|c|c|c|c|c|c|c}
\hline$A^{s s}$ & $Y^{s s}$ & $C^{s s}$ & $L^{s s}$ & $K^{s s}$ & $I^{s s}$ & $r^{s s}$ & $w^{s s}$ & $K_{0}$ & $B$ \\
\hline \hline 1.000 & 0.105 & 0.080 & 0.304 & 1.000 & 0.025 & 0.035 & 0.231 & 0.500 & 0.233 \\
\hline
\end{tabular}

Fig. 1 shows the responses of each economic variable when an one-off positive productivity shock occurs in period 0 . The shock affects the same percentage of output of both economies in the steady state and in the transitional path. Fig. 1 (1) to (6) show the paths and trends ${ }^{2}$. The blue lines are the paths in the case that the shock occurs at the steady state and the red lines are the paths in the case that the shock occurs at the half of steady

2) Because this journal is printed in black and white only, even though the figures in the original paper were prepared for color production, it is impossible to recognize which one are blue and which one are red lines. For the readers who are interested in the figures, the author provides the original figures at http://www2.asia-u.ac.jp/ shin. 
(1) $\operatorname{Shock}(\mathrm{A})$

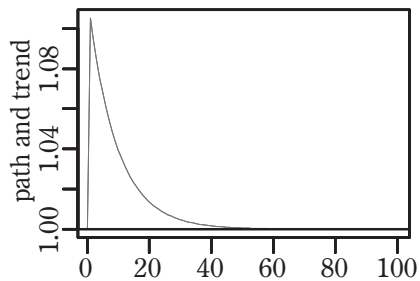

(4) Labor

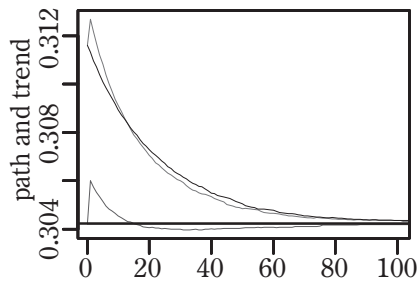

(7) $\operatorname{Shock}(\mathrm{A})$

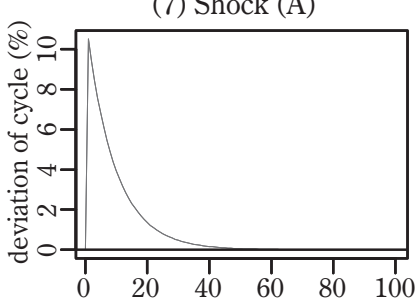

(10) Labor

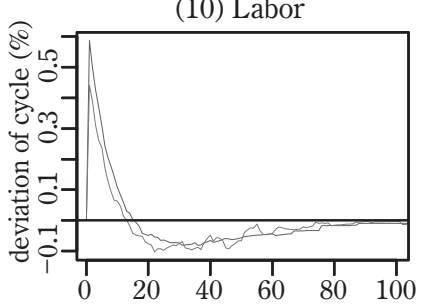

(2) Output

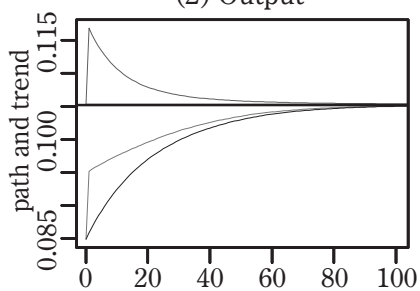

(5) Capital

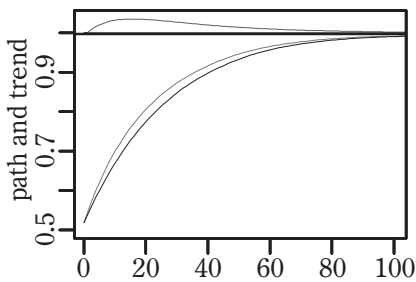

(8) Output

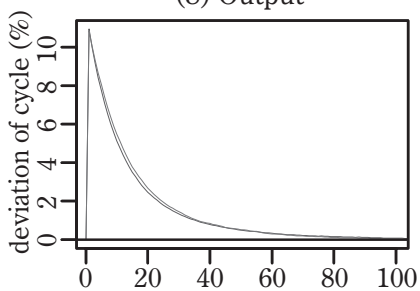

(11) Capital

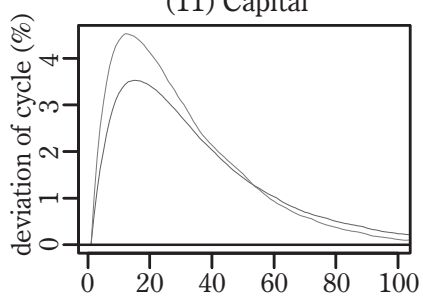

(3) Consumption

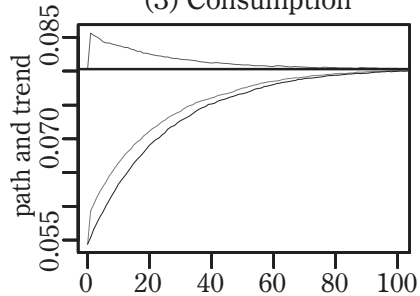

(6) Investment

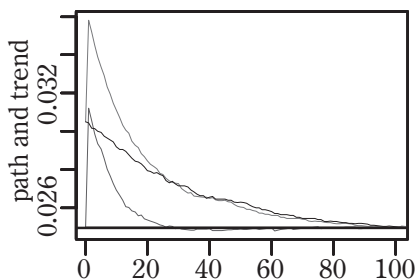

(9) Consumption

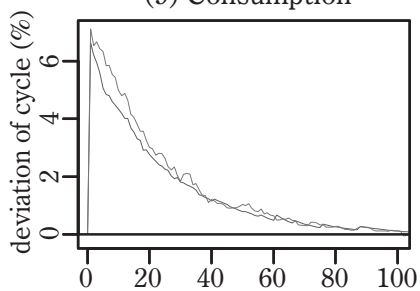

(12) Investment

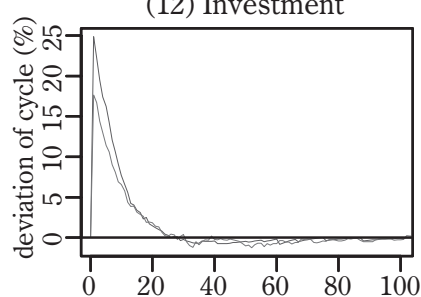

Figure 1 responses to an one-off positive productivity shock

state level of capital ${ }^{3)}$. All variables respond positively to the positive productivity shock. Although there are differences between the blue lines and the red lines in the early part of paths, the differences diminish as time goes. It shows that the economic variables starting from the transitional path (the red lines) converge to the steady state. The black lines are trends. The trends were defined as the transitional paths with no shock. The horizontal lines represent the steady state values.

Fig. 1 (7) to (12) show the deviation rates of the cycle from the trend. The deviation rate

3) We drew the blue lines first and the red lines next. Because the shock was common, in Fig. 1 (1) and (7), the blue lines were overlaid with the red lines. We can see only red lines in Fig. 1 (1) and (7). 


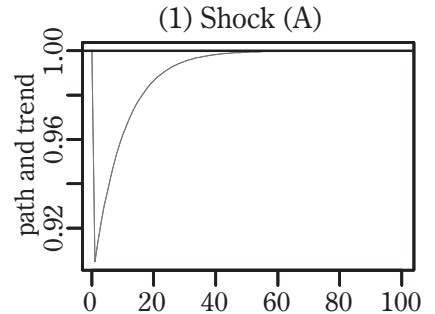

(4) Labor

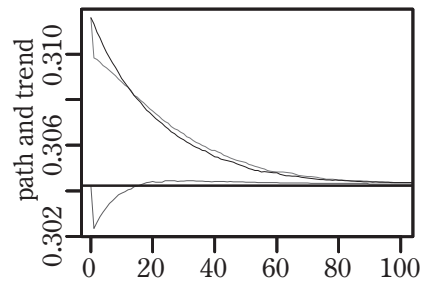

(7) Shock (A)
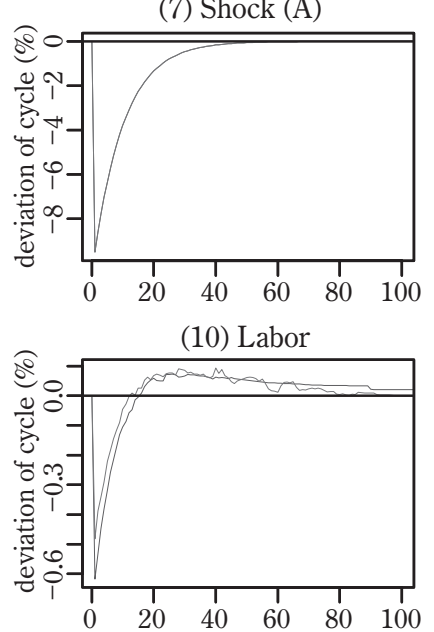

(2) Output

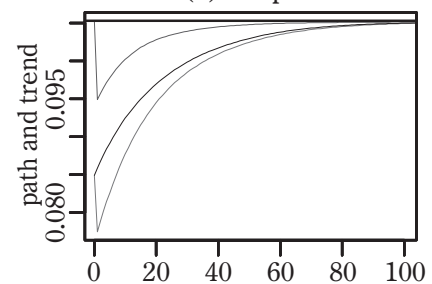

(5) Capital

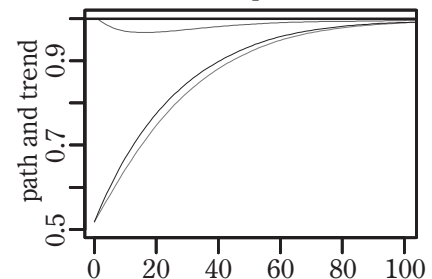

(8) Output

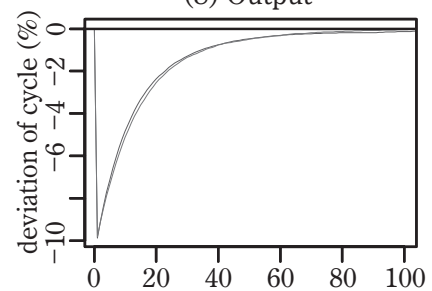

(11) Capital

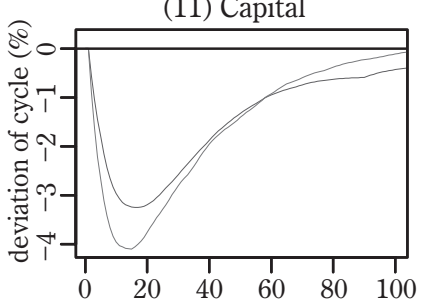

(3) Consumption

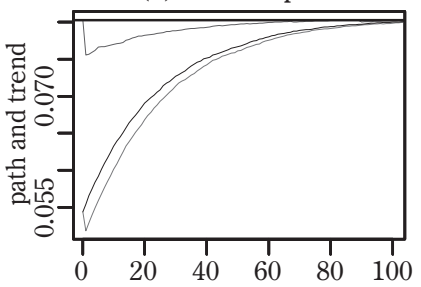

(6) Investment

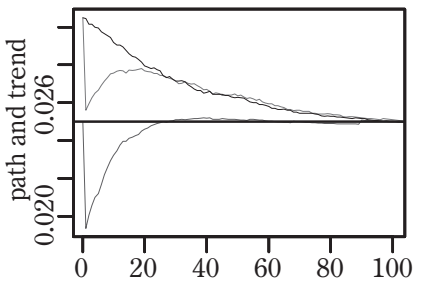

(9) Consumption

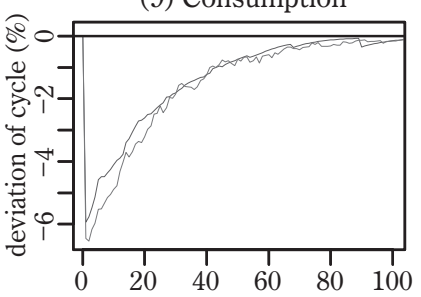

(12) Investment

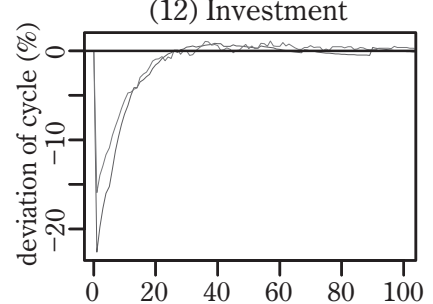

Figure 2 responses to an one-off negative productivity shock

was calculated from the cycle being divided by trend, that is, deviation rate $=\frac{\text { path-trend }}{\text { trend }} \times 100$. In Fig. 1 (9) and (11), the peaks of red lines are higher than the peaks of the blue lines. On the contrary, in Fig. 1 (10) and (12) the peaks of blue lines are higher than the peaks of the red lines. The consumption and the capital stock response more to the productivity shock when the economy is at early stage, which is a characteristic of a developing country. By contrast, the labor and the investment response more to the productivity shock when the economy is near steady state, which is a characteristic of a developed country.

Fig. 2 shows the responses of each economic variable when an one-off negative productivity shock occurs in period 0 . The shock also affects the same percentage of output of both 
economies in the steady state and in the transitional path as Fig. 1. The way to read Fig. 2 is the same with that of Fig. 1. In Fig. 2 (1) to (6), all variables respond negatively to the negative productivity shock and the economic variables starting from the transitional path converge to the steady state. The differences fade away finally as time goes. In Fig. $2(9)$ and (11), the valleys of red lines are deeper than the valleys of the blue lines. On the contrary, in Fig. 2 (10) and (12) the valleys of blue lines are deeper than the valleys of the red lines. The consumption and the capital stock response more to the productivity shock when the economy is at early stage, which is a characteristic of a developing country. By contrast, the labor and the investment response more to the productivity shock when the economy is near steady state, which is a characteristic of a developed country. These results are the same with the outcome when the positive productivity shock occurs as we have seen in Fig. 1.

Table 2 comparison of deviation of cycle

\begin{tabular}{|c|c|c|c|c|c|}
\hline & & $C$ & $L$ & $K$ & $I$ \\
\hline \multirow{4}{*}{$\begin{array}{l}\text { height of the peaks } \\
\text { (positive shock) }\end{array}$} & $\begin{array}{l}\text { (1) Shock occurs near } \\
\text { steady state (blue lines) }\end{array}$ & 6.62 & 0.59 & 3.53 & 24.86 \\
\hline & $\begin{array}{l}\text { (2) Shock occurs on tran- } \\
\text { sitional path (red lines) }\end{array}$ & 7.11 & 0.44 & 4.53 & 17.63 \\
\hline & $\frac{(2)-(1)}{(1)} \times 100$ & 7.44 & -24.94 & 28.39 & -29.06 \\
\hline & comparison & $(1)<(2)$ & $(1)>(2)$ & $(1)<(2)$ & $(1)>(2)$ \\
\hline \multirow{4}{*}{$\begin{array}{l}\text { depth of the valleys } \\
\text { (negative shock) }\end{array}$} & $\begin{array}{l}\text { (3) Shock occurs near } \\
\text { steady state (blue lines) }\end{array}$ & 5.93 & 0.62 & 3.25 & 22.60 \\
\hline & $\begin{array}{l}\text { (4) Shock occurs on tran- } \\
\text { sitional path (red lines) }\end{array}$ & 6.54 & 0.48 & 4.10 & 15.92 \\
\hline & $\frac{(4)-(3)}{(3)} \times 100$ & 10.30 & -21.85 & 26.24 & -29.56 \\
\hline & comparison & $(3)<(4)$ & $(3)>(4)$ & $(3)<(4)$ & $(3)>(4)$ \\
\hline
\end{tabular}

We measure the height of the peaks and the depth of the valleys. Table 2 shows the largest deviation rates of each economic variable. Even though the external productivity shocks are common, the size of responses to the same shock is different depending on the economic development stages. The differences are quite big. The range for the differences of the deviation rates between the blue lines and the red lines is about $7 \%$ to $30 \%$. In the case of capital stock and investment, the differences of deviation rate are about $30 \%$. Of course, the differences will be diminished, as the initial level of capital stock is closer to the steady state.

Fig. 3 shows the responses of each economic variable when productivity shock occurs consecutively from period 0. The productivity shock follows from Eq. (6). Fig. 1 (1) to (6) show the paths and trends of each variable and Fig. 3 (7) to (12) show the deviation rates 
(1) Shock (A)

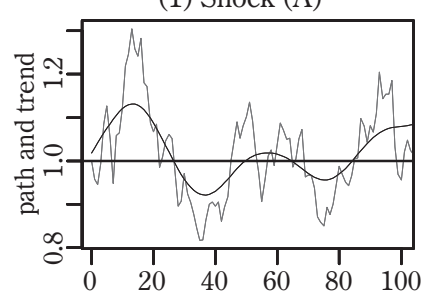

(4) Labor

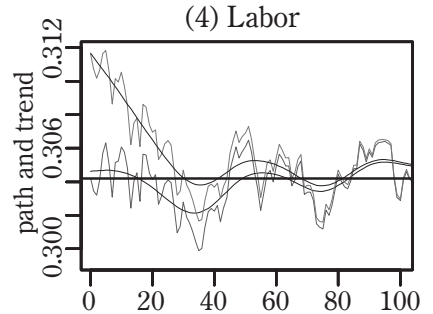

(7) Shock (A)

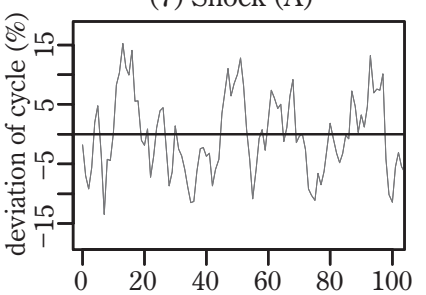

(10) Labor

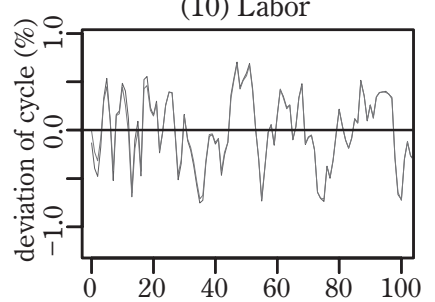

(2) Output

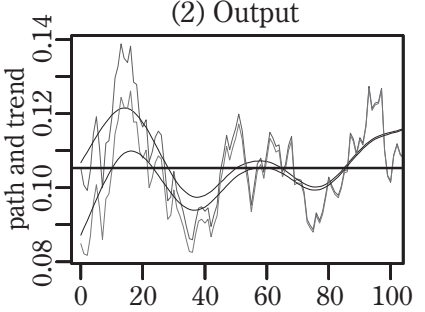

(5) Capital

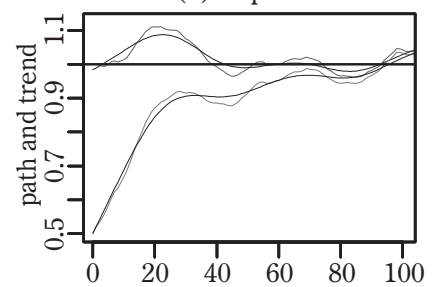

(8) Output

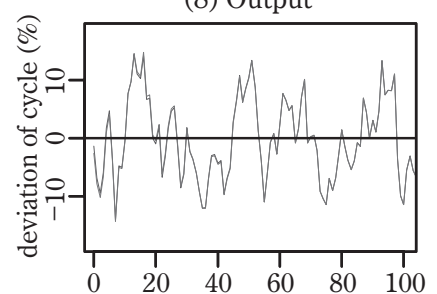

(11) Capital

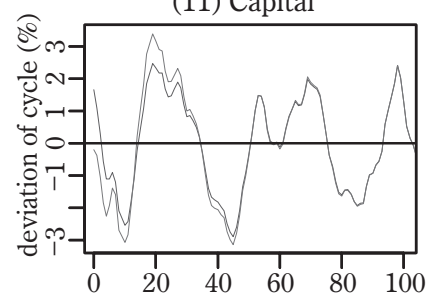

(3) Consumption

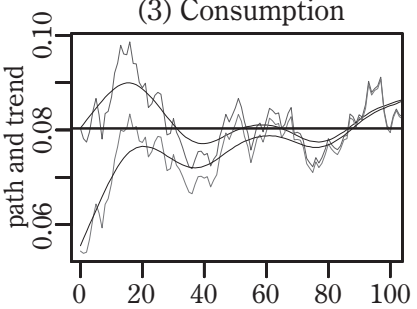

(6) Investment

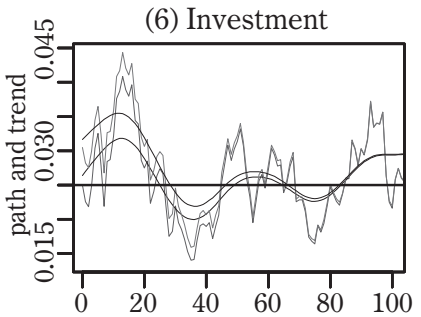

(9) Consumption

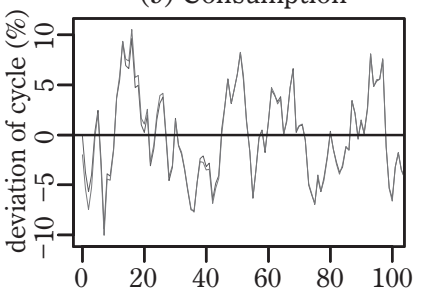

(12) Investment

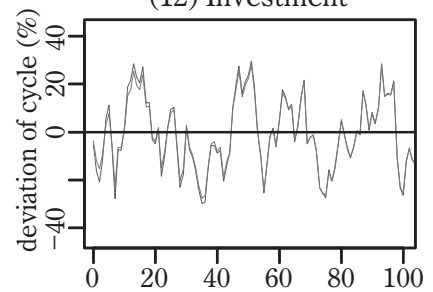

Figure 3 responses to consecutive shock

of each variable. The blue lines are the paths in the case that the shock occurs from the steady state and the red lines are the paths in the case that the shock occurs from the half of steady state level of capital stock as Fig. 1 and Fig. 2. The black lines are trends. The trends were calculated using Hodrick-Prescott filter. The horizontal lines in Fig. 3 (1) to (6) represent the steady state values. Although there are differences between the blue lines and the red lines in the early part of paths, it can be seen that there is almost no difference as the economy approaches the steady state. It shows that the economic variables starting from the transitional path converge to the steady state even if there are continuative shocks. Since the economic variables converge to steady state over time, the difference between the deviation 
in the transitional path and the deviation in the steady state also naturally shrinks.

We compare the economy at the early stage of development and the economy near the steady state. As seen at the beginning part of Fig. 3 (9) and (11), the consumption and the capital stock in the economy at early stage of development (red lines) fluctuate more compared to those in the economy near steady state (blue lines). On the contrary, at the beginning part of Fig. 3 (10) and (12), the labor and the investment in the economy near steady state (blue lines) fluctuate more compared to those of the economy at early stage of development (red lines).

We guess the possible reason, that the sizes of the volatility of economic variables are different despite the same shock, which affects the same percentage of output of both economies, could lie in the fact that the sizes of economic variables are different depending on the development stages. There are sayings - a deeply rooted tree never sways in the wind; still waters run deep. In the case of consumption and capital stock, the values at the steady state are larger than the values on the transitional path. On the other hand, in the case of labor and investment, the values on the transitional path are larger than the values at the steady state. It is considered that the larger the value of the economic variables is, the smaller the deviation rate is, oppositely, the smaller the value of the economic variables is, the bigger the deviation rate is. However, we want to remind you again that this is just an intuitive explanation, and not theoretical one, of the possible mechanisms behind the obtained results, that will be discussed in the next research ${ }^{4}$.

\section{Conclusion}

In this research, we analyzed the size of the responses of the economic variables to external shocks depending on the development stages. We compared the volatility of economic variables at early stage of development with the volatility of economic variables near steady state.

Even though the external productivity shock was the same, the sizes of the responses of economic variables to the common shocks were quite different since the scale of economy varied depending on the stages of development. The range for the differences of the deviation rates is about $7 \%$ to $30 \%$. In the case of capital stock and investment, the differences of deviation

4) For instance, the higher response of labor when the shock occurs at the steady state can be explained by the fact that, in the initial equilibrium, the marginal product and marginal disutility of labor are respectively higher and lower than what is the case during the transition, etc. 
rate were about 30\%. This research made the differences clear using the numerical analysis. This is the main contribution of this research. In the case of consumption and capital stock, the deviation rates at the early stage of development are larger than the deviation rates near the steady state. On the other hand, in the case of labor and investment, the deviation rates at the early stages of development are smaller than the deviation rate near the steady state.

Considering the real factor that most of the countries are on their transitional path not in their steady state, these countries should consider the differences when they analyze their economic fluctuations using the analysis near steady state. If not, the fluctuations can be overestimated or underestimated. It will be necessary for developing countries to analyze their economies not only near the steady state but also on their transitional path.

\section{References}

[1] Blanchard, Olivier J. and Kahn, Charles M., 1980, The solution of linear difference models under rational expectations, Econometrica, Vol.48, No.5, pp.1305-1311.

[2] Heer, Burkhard and Maussner, Alfred, 2009, Dynamic General Equilibrium Modeling: Computational Methods and Applications, Springer Berlin Heidelberg.

[ 3 ] Judd, Kenneth L., 1998, Numerical Methods in Economics, MIT Press.

[4] King, Robert G., Plosser, Charles I. and Rebelo, Sergio T., 1988, Production, growth and business cycles: I. The basic neoclassical model, Journal of Monetary Economics, Vol.21, Issue 2-3, pp.195-232.

[5] Klein, Paul, 2000, Using the generalized schur form to solve a multivariate linear rational expectations model, Journal of Economic Dynamics and Control, Vol.24, Issue 10, pp.1405-1423.

[6] Kydland, Finn E. and Prescott, Edward C., 1982, Time to Build and Aggregate Fluctuations, Econometrica, Vol.50, No.6, pp.1345-1370.

[7] McCandless, George, 2008, The ABCs of RBCs: An Introduction to Dynamic Macroeconomic Models, Harvard University Press.

[ 8 ] Sims, Christopher A., 2002, Solving linear rational expectations models, Computational Economics Vol.20, No.1-2, pp.1-20.

[9] Uhlig, Harald., 1999, A toolkit for analyzing nonlinear dynamic stochastic models easily, in Marimon Ramon and Scott Andrew (eds.), Computational Methods for the Study of Dynamic Economics, pp.30-61, Oxford University Press. 